\title{
New Pseudopterosin and seco-Pseudopterosin Diterpene Glycosides from Two Colombian Isolates of Pseudopterogorgia elisabethae (Octocorallia) and Their Diverse Biological Activities
}

Ileana I. Rodríguez, Yan Ping Shi, Oscar J. García, Abimael D. Rodríguez, Alejandro M. S. Mayer, Juan A. Sánchez, Eduardo Ortega-Barria, and José González

Department of Chemistry, University of Puerto Rico, P.O. Box 23346, U.P.R. Station, San Juan, Puerto Rico 00931-3346, Department of Pharmacology, Chicago College of Osteopathic Medicine, Midwestern University, $55531^{\text {st }}$ Street, Downers Grove, Illinois 60515, Department of Systematic Biology \& Laboratories of Analytical Biology, Smithsonian Institution, P.O. Box 37012, Washington, D.C. 200137012, Instituto de Investigaciones Científicas Avanzadas y Servicios de Alta Tecnología, Centro de Estudios Biomédicos, Clayton, Building 175, P.O. Box 7250, Panama 5, Republic of Panama

\section{Supporting Information}

${ }^{1} \mathrm{H}$ NMR $(500 \mathrm{MHz})$ and ${ }^{13} \mathrm{C}$ NMR (125 MHz) Spectra of Pseudopterosin P (1)

${ }^{1} \mathrm{H}$ NMR $(500 \mathrm{MHz})$ and ${ }^{13} \mathrm{C}$ NMR (125 MHz) Spectra of Pseudopterosin U (6)

${ }^{1} \mathrm{H}$ NMR (500 MHz) and ${ }^{13} \mathrm{C}$ NMR (125 MHz) Spectra of Pseudopterosin Z (11) 


\section{${ }^{1} \mathrm{H}$ and ${ }^{13} \mathrm{C}$ NMR Spectra $\left(\mathrm{CDCl}_{3}\right)$ of Pseudopterosin P (1)}

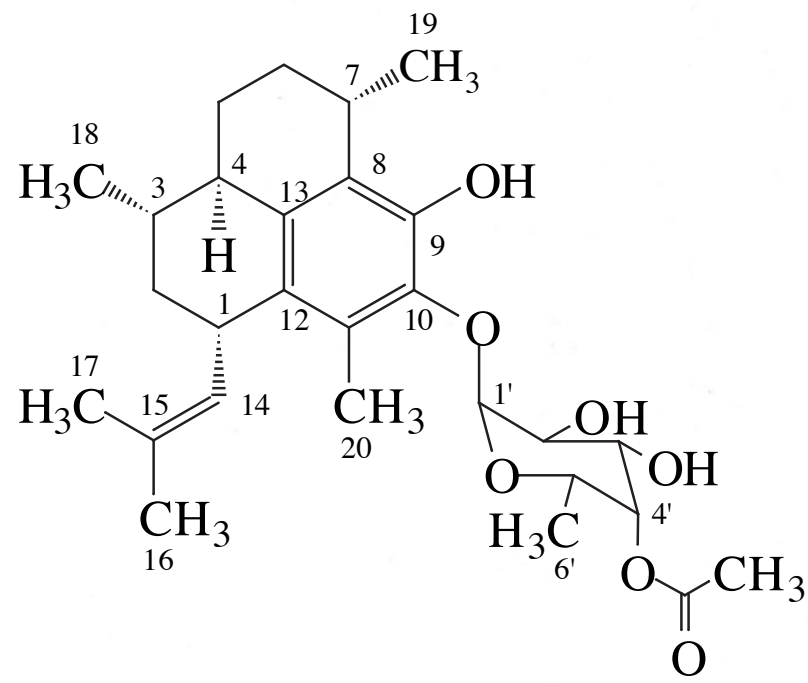

-OAc

Me20
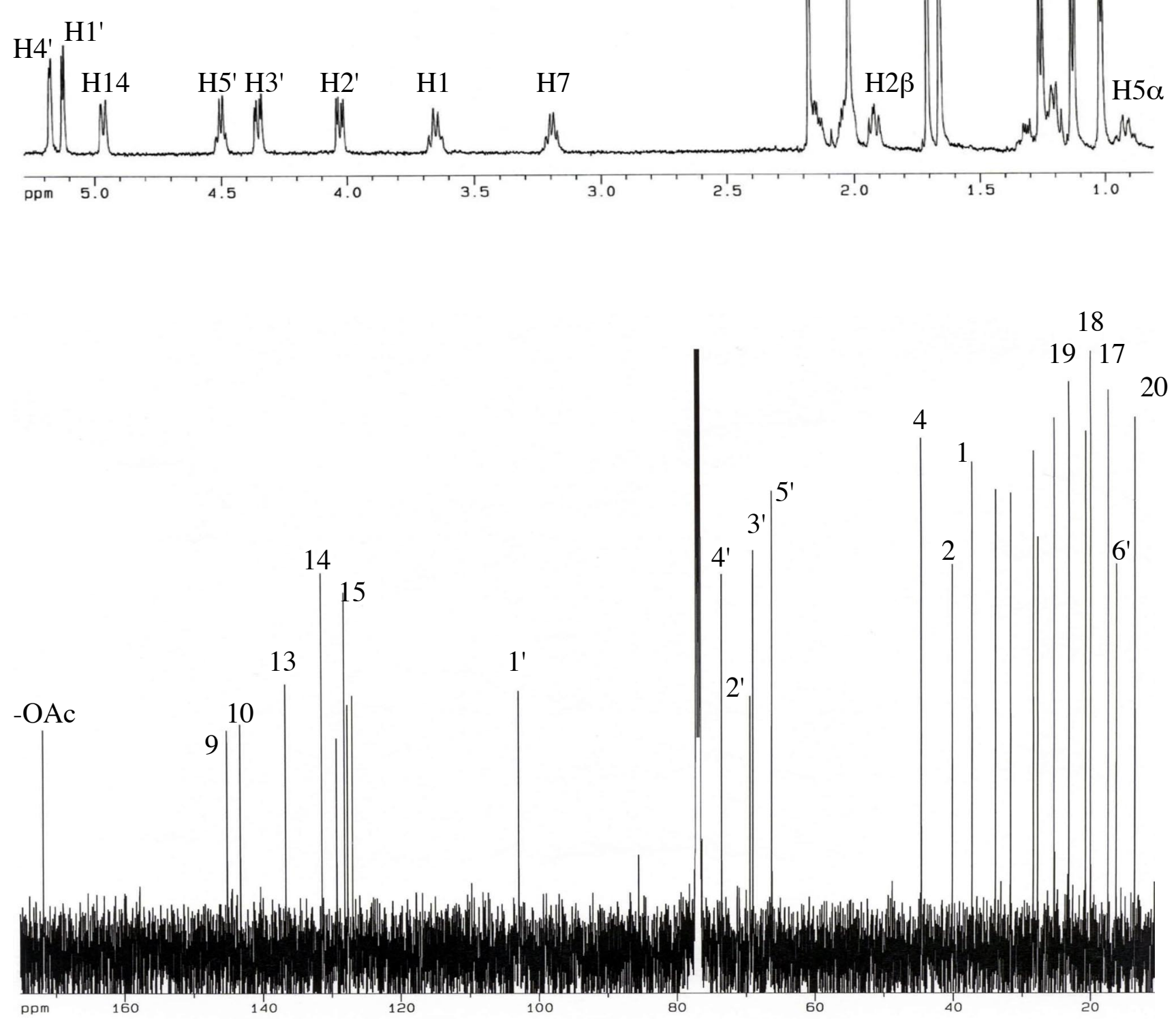


\section{${ }^{1} \mathrm{H}$ and ${ }^{13} \mathrm{C}$ NMR Spectra $\left(\mathrm{CDCl}_{3}\right)$ of Pseudopterosin U (6)}
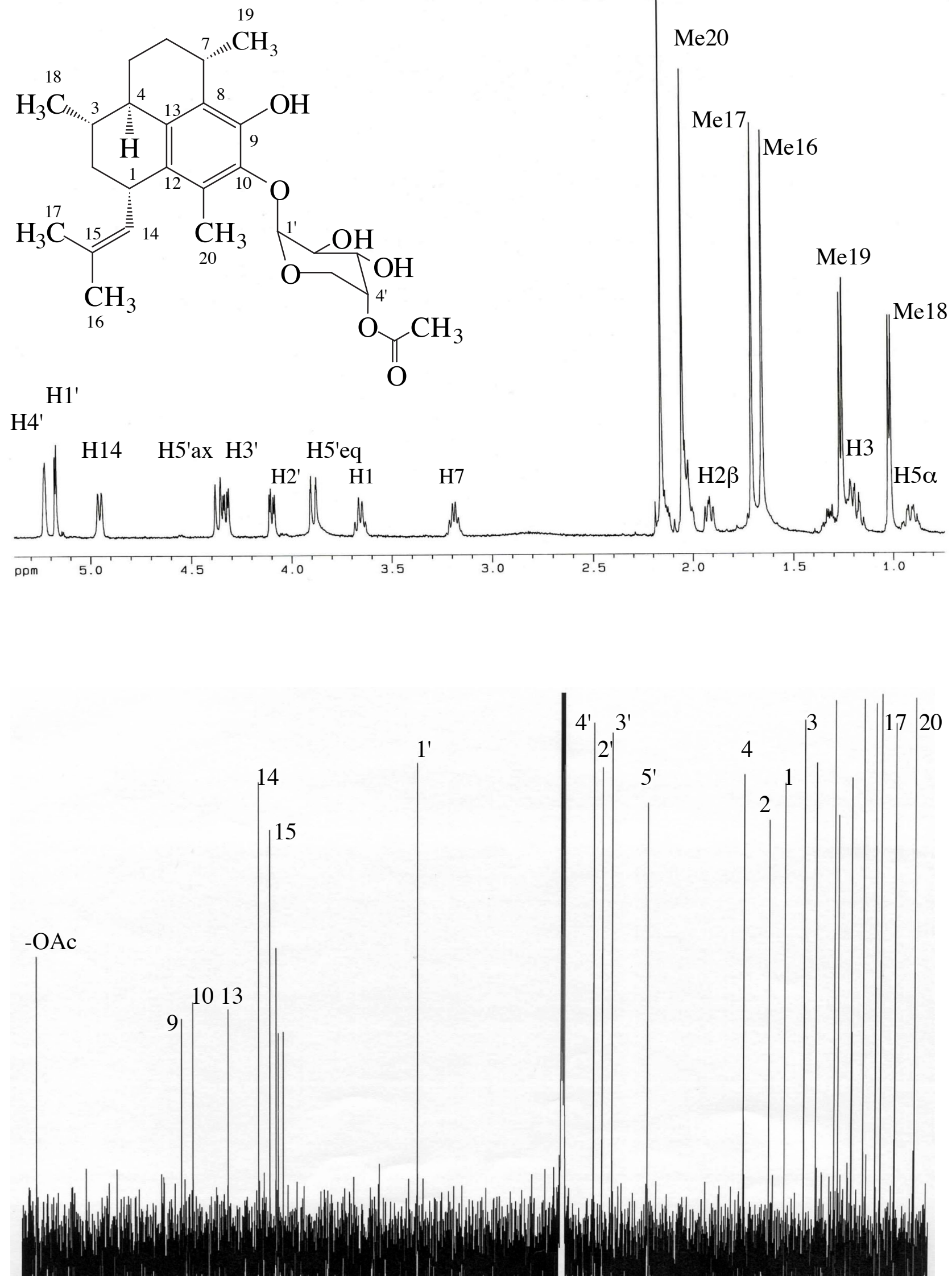


\section{'H and ${ }^{13} \mathrm{C}$ NMR Spectra $\left(\mathrm{CDCl}_{3}\right)$ of Pseudopterosin $\mathrm{Z}(11)$}

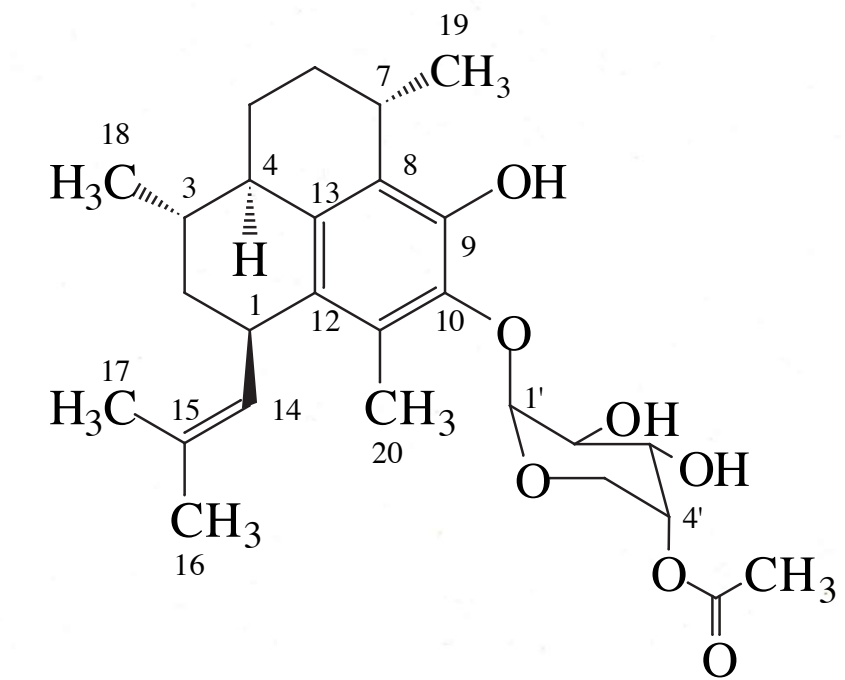

-OAc
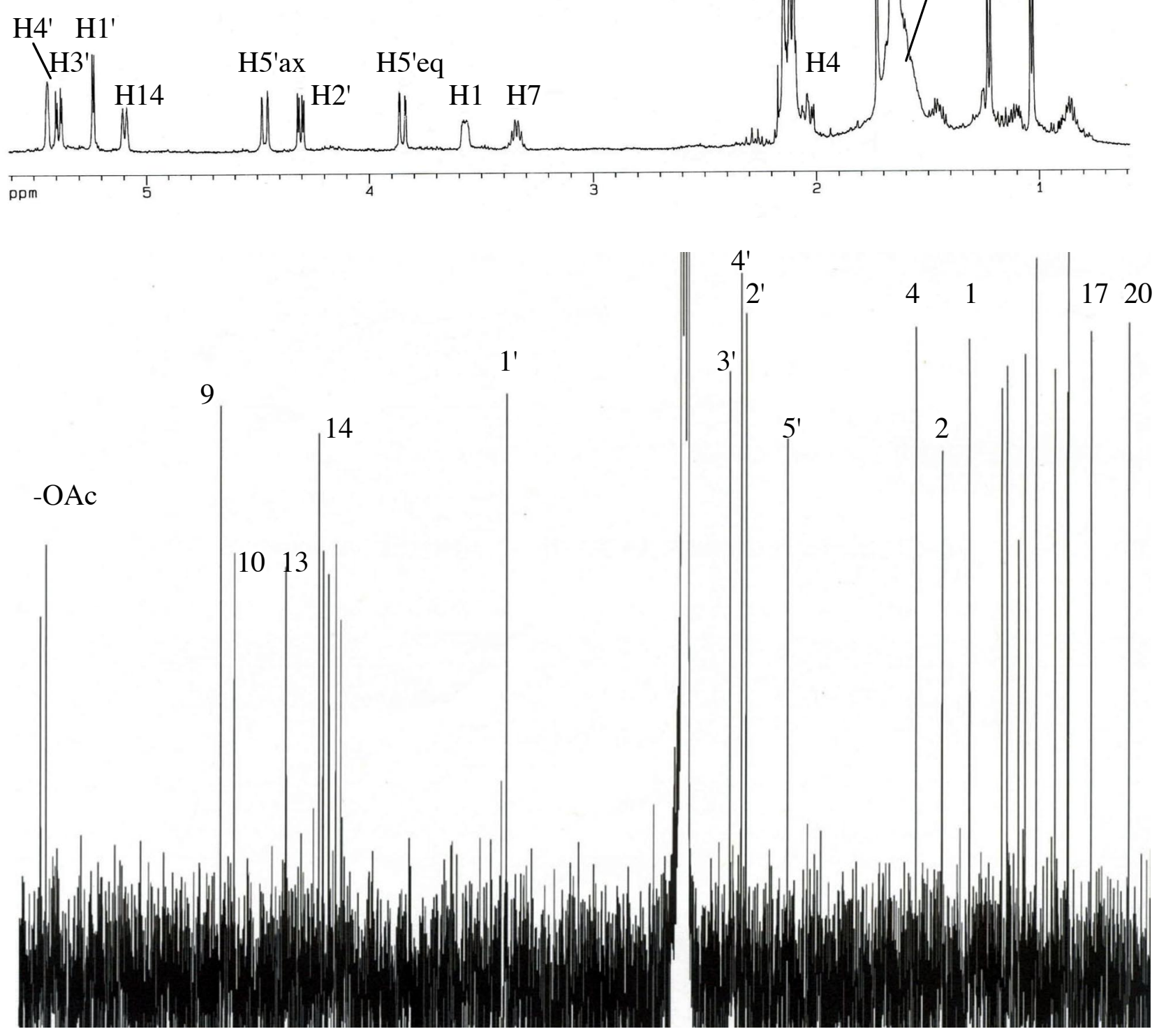